SAINS TANAH - Journal of Soil Science and Agroclimatology

Journal homepage: http://jurnal.uns.ac.id/tanah

\title{
A numerical estimate of water level elevation due to a cyclone associated with a different landfall angle
}

\author{
Md. Abdul Al Mohit ${ }^{1}$, Md. Towhiduzzaman ${ }^{2}$ \\ ${ }^{1}$ Department of Mathematics, Islamic University, Kushtia-7003, Bangladesh \\ ${ }^{2}$ Department of Electrical \& Electronic Engineering (EEE), Uttara University (UU), Dhaka-1230, Bangladesh
}

\begin{tabular}{|c|c|}
\hline ARTICLE INFO & ABSTRACT \\
\hline Keywords: & angladesh is a disaster-prone riverine country in South $A$ \\
\hline AGCM & lated. That's why re \\
\hline Bangladesh & ivestigates the surge height associated with the changes of landfall angle due to climate \\
\hline Climate & change. The deflected angle of landfall was investigated from the data analysis of \\
\hline Cyclone & angladesh Meteorological Department (BMD), Joint typhoon warning center (JTWC), and \\
\hline Surge & $\begin{array}{l}\text { Meteorological Research Institute- Atmospheric global circulation model (MRI-AGCM). A } \\
\text { cyclone of future climate has been investigated from the Database for Policy Decision- }\end{array}$ \\
\hline Article history & Making for Future Climate Change (d4PDF) data under present and future climate \\
\hline Submitted: 2021-11-19 & nditions. To find the surge height, a vertically shallow water Cartesian coordinate model \\
\hline Accepted: 2022-02-09 & has been used to simulate the surge height. The shallow water model equations were \\
\hline Available online: $2022-03-02$ & discretized through finite difference technique with the Arakawa $\mathrm{C}$ grid system and solved \\
\hline Published regularly: June 2022 & $\begin{array}{l}\text { by a conditionally stable semi-implicit manner. The fluctuated striking angle due to climate } \\
\text { change was then applied to the known cyclone BOB } 01 \text { and the associated surge height }\end{array}$ \\
\hline ng Author & was then investigated. We found that our simulated result and the observed result make \\
\hline $\begin{array}{l}\text { Email address: } \\
\text { towhid.math.iu@gmail.com }\end{array}$ & a good agreement. We have also seen that different types of cyclones have a significant \\
\hline
\end{tabular}

How to Cite: Al Mohit, M.A. \& Towhiduzzaman, M. (2022). A numerical estimate of water level elevation due to a cyclone associated with a different landfall angle. Sains Tanah Journal of Soil Science and Agroclimatology, 19(1): 33-41. https://dx.doi.org/10.20961/stjssa.v19i1.56600

\section{INTRODUCTION}

Bangladesh is a disaster prone small country in South Asia. The natural hazards of this country are increasing due to global warming. According to the World Bank Group, Bangladesh will be faced with various problems due to the vulnerability to climate change (Al Mohit, Yamashiro, Hashimoto, et al., 2018). Some factors are mainly responsible for this vulnerability; the factors are densely populated, lowlying topography, coastal structure, funneling shape of the coast, El Nino Southern Oscillation, human activity, and so on. The major concern is that the catastrophic cyclone strikes Bangladesh in the next upcoming year due to global warming (Al Mohit, Yamashiro, Ide, et al., 2018). According to Al Mohit, Yamashiro, Hashimoto, et al. (2018), there are 269 depressions found in the Bay of Bengal in the last 44 years. But, it is found in the last 25 years (1974-1999) that the average depression rate of that period is $7.7,3.46$ of the depression formed as a matured storm and 3.12 of storm strikes on the Bay of Bengal coast. Every year, the characteristics of the storm are changed due to global warming and climate change (Kotal \& Bhattacharya, 2013).

Some authors investigated the cyclone track features and tidal phase shift for the surge simulation (Hussain \& Tajima, 2017). Hussain did further development of the same work. In their study, they investigated the parallel track features impact on surge behavior. They found that the changes in surge height occurred due to parallel track features (Hussain et al., 2017). This study focuses on cyclone strike angle due to climate change and associated storm surge behavior along the Bay of Bengal. That's why we have used our own developed model to estimate the surge behavior. Many analyses of storm surges due to the tropical storm have been made for the Bay of Bengal region covering the coastal area of Bangladesh and the east coast of India (Al Mohit, Yamashiro, Hashimoto, et al., 2018; Antony \& Unnikrishnan, 2013; Dube, 2012; Jaman et al., 2021; Paul \& Ismail, 2012; Paul et al., 2021). Some of their studies were on the behavior of silt on the coast after storms. The 
linear storm surge model was developed (Tadesse et al., 2020), which was the first nested model for storm surge simulation. Paul et al. (2021) provide the information about tide surge interaction model and the interaction with tide and surge associated with a storm nonlinearly for the accurate prediction of the magnitude and time of the peak of water level on the oceanographic scale.

However, the first nonlinear model made a good agreement with observed data but it had some limitations. Further, the model was developed and recently considered an atmospheric model with this model (Mamnun et al., 2020). Most of the researchers try to incorporate various marine dynamics. Al Mohit, Yamashiro, Hashimoto, et al. (2018) incorporate the dynamic effect of the Ganges-BrahmaputraMeghna river system in Bangladesh and offshore islands in his model. The proper stair step process represented the offshore islands. Nevertheless, they consider the Meghna estuarine region including only two major offshore islands Sandwip and Hatiya. Paul and Ismail (2013) found that the low-lying small and big lands and offshore islands may influence surge intensity. Furthermore, they develop the model of Paul (Paul \& Ali, 2019) by nesting a very fine grid model into the fine grid model as well as extending the fine grid model for the whole coastal belt to incorporate the offshore island properly. To find the surge height accurately, Al Mohit, Yamashiro, Hashimoto, et al. (2018) developed a two dimensional bay-river coupled model incorporating the Ganges-Brahmaputra-Meghna river system. However, these works were done for the storm surge simulation in the Bangladesh coast, but none of them considers the climate change impact on surge simulation. Nowadays, it is important to investigate the global warming impact on surge height simulation (Ramos-Valle et al., 2020). For the storm surge simulation, the important factors are low pressure, maximum wind speed, forward movement, storm size, coastal shape, and so on (Musinguzi \& Akbar, 2021; Shankar \& Behera, 2019). So, we analyze the climate data to investigate the behavior of a cyclone within the Bay of Bengal. All the work was on the storm surge simulation within the Bay of Bengal, but this study investigated climate data and checked the cyclone strike angle behavior. After that, based on the changes of strike angle storm surge was estimated.

In this study, storm surge height has been investigated as well as the landfall angle impact on the storm surge height. The fluctuated landfall angle was investigated from the d4PDF present and future track information. The result found that the future landfall angle might reduce the surge height when the crossing angle is greater than 90 degrees.

\section{DATA MATERIALS AND METHODS}

\subsection{Study area}

Bangladesh is a cyclone disaster-affected country. The astronomical position of the country is $88^{\circ} \mathrm{E}$ to $92^{\circ} \mathrm{E}$ longitudes and $20^{\circ} \mathrm{N}$ to $26^{\circ} \mathrm{N}$ latitude. In this study, we have considered the study area $85^{\circ} \mathrm{E}$ to $95^{\circ} \mathrm{E}$ longitude and $25^{\circ} \mathrm{N}$ to $23^{\circ} \mathrm{N}$ latitude to investigate the surge height. We Have considered this area to investigate a storm for at least three days within this domain. However, we have collected the cyclone track information from the d4PDF data within the region of $75^{\circ} \mathrm{E}$ to $95^{\circ} \mathrm{E}$ longitude and $5^{\circ} \mathrm{N}$ to $30^{\circ} \mathrm{N}$ latitude.

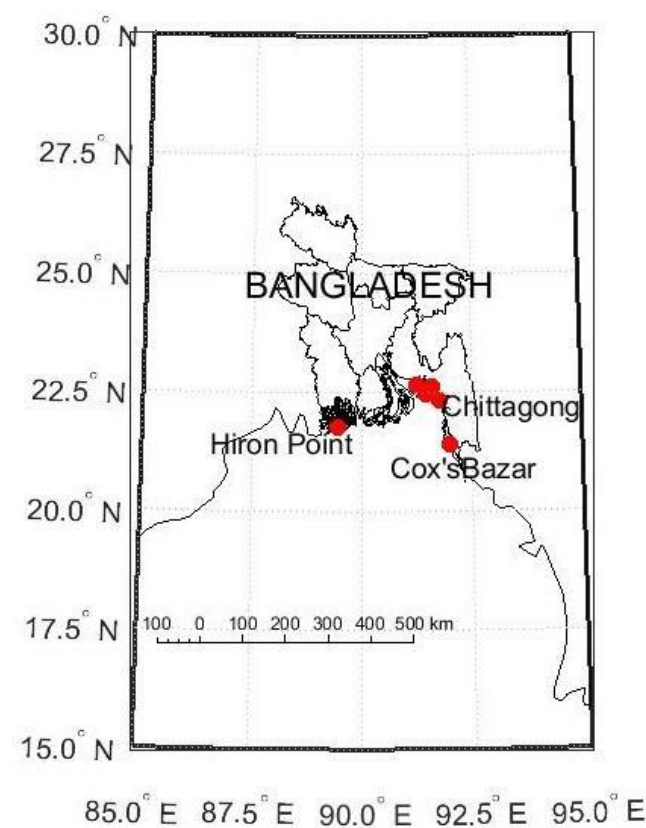

Figure 1. Bangladesh coastal area with the tidal station location information

Figure 1 can explain the investigated study area. The color marked point is the tidal station near the coast of Bangladesh. Bangladesh Inland Water Transport Authority (BIWTA) has the exclusive legal rights to access the data. The authority processed the observed data and provided the data for further analysis. However, not all the stations are digital at all, so for this reason the observed data scarcity is common in this region. Due to the low land area and complex coastal shape, the surge height has fluctuated in the different coastal positions.

\subsection{The data}

This study exercises the d4PDF, AGCM, and BMD data. The d4PDF data consists of the output of $60 \mathrm{~km}$ atmospheric global circulation model (AGCM) and Meteorological Research Institute (MRI). This model is operated by the Japan meteorological agency. To find the accuracy of regional data, a proper downscaling is used for the Japan region. But, this study used the $20 \mathrm{~km}$ grid data to find the general scenario of cyclone track behavior around the Bay of Bengal. In the d4PDF model simulation data, the computation grid cell was $640 \times 320$ grids in horizontal level and 64 grids in the vertical level. The d4PDF model is simulated with the model of MRIAGCM 3.2 and MRI-AGCM3.2H (Mizuta et al., 2012). The d4PDF present data consists of the 100 member's ensemble simulations and the future data experiments are CCSM4 (CC), GFDL-CM3 (GF), HadGEM2-AO (HA), MIROC5 (MI), MPI-ESM$\mathrm{MR}(\mathrm{MP}), \mathrm{MRI}-\mathrm{CGCM} 3$ (MR). For each experiment, there are 15 members and the total ensemble members are 90 for future climate experiments. In this study, we have used 100 members simulation data for the present climate scenario analysis and six scenarios with 15 members in each scenario (a total of 90 members) were used for future climate analysis. Figure 2 represents the SST for the different scenario and present climate AGCM track that strikes the Bangladesh coast. 

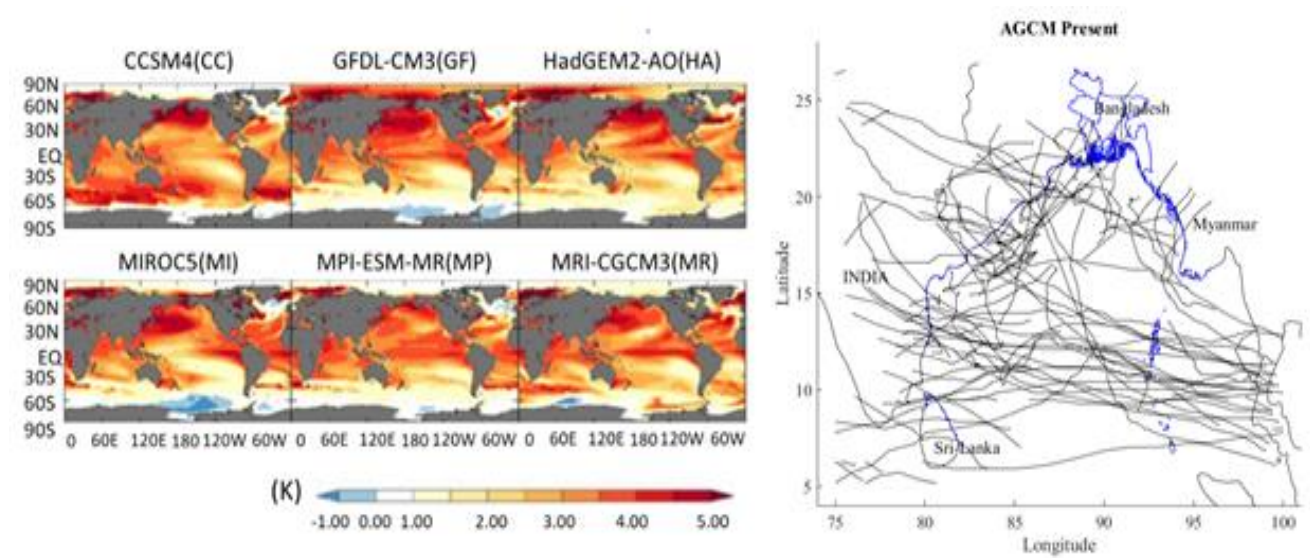

Figure 2. Different Scenario SST (left), Present climate track of AGCM (right)

\subsection{Mathematical model}

A vertically shallow water model is used to simulate the surge height. The model input is taken from the Bangladesh Meteorological Department (BMD). We have considered the cyclone BOB 01 known as cyclone 1991. The fluctuated landfall angle is considered to simulate the surge height. The original landfall angle of the cyclone 1991 was 88.97 degrees. But, in our model simulation, we have changed the cyclone track one degree from 85 to 93 degree angle. The mean landfall angle shifted from 91.0373 to 93.9193 degrees due to climate change.

From the concepts of atmospheric or oceanic phenomenon, the z-component of the momentum equation may be approximated by the hydrostatic equation when the horizontal length scale is much larger than the vertical scale and the continuity equation may reduce to the nondivergence of velocity, the density variation in all directions is negligible and neglecting the molecular viscosity of the oceanic fluid, the basic shallow water equations are as follows $\frac{\partial u}{\partial t}+u \frac{\partial u}{\partial x}+v \frac{\partial u}{\partial y}+w \frac{\partial u}{\partial z}-f v=-\frac{1}{\rho} \frac{\partial p}{\partial x}$

$\frac{\partial v}{\partial t}+u \frac{\partial v}{\partial x}+v \frac{\partial v}{\partial y}+w \frac{\partial v}{\partial z}-f u=-\frac{1}{\rho} \frac{\partial p}{\partial y}$

$\frac{\partial p}{\partial z}=-\rho g$

$\frac{\partial u}{\partial x}+\frac{\partial v}{\partial y}+\frac{\partial w}{\partial z}=0$

Where $u, v, w$ are the instantaneous components of velocity in the directions of $x, y$, and $z$, respectively; $t$ is the time; $p$ is the pressure; $\rho$ is the density of seawater that is considered to be uniform and incompressible; $f=2 \Omega$ $\sin \sin \varphi$ is the Coriolis parameter, where $\Omega$ is the angular speed of the earth rotation and $\varphi$ is the latitude of the field of view; $g$ is the acceleration due to gravity.

After averaging procedure and vertically integrated the equation, the model equation can be written in the final form $\frac{\partial \zeta}{\partial t}+\frac{\partial \widetilde{u}}{\partial x}+\frac{\partial \tilde{v}}{\partial y}=0$

$\frac{\partial \widetilde{u}}{\partial t}+\frac{\partial(u \tilde{u})}{\partial x}+\frac{\partial(v \widetilde{u})}{\partial y}-f \tilde{v}=-g(\zeta+h) \frac{\partial \zeta}{\partial x}+\frac{T_{x}}{\rho}-$

$\frac{C_{f} \check{u} \sqrt{\left(u^{2}+v^{2}\right)}}{\zeta+h}$

$\frac{\partial \tilde{v}}{\partial t}+\frac{\partial(u \tilde{v})}{\partial x}+\frac{\partial(v \tilde{v})}{\partial y}+f \tilde{u}=-g(\zeta+h) \frac{\partial \zeta}{\partial x}+\frac{T_{y}}{\rho}-$

$\frac{C_{f} v \sqrt{\left(u^{2}+v^{2}\right)}}{\zeta+h}$

Where $(\tilde{u}, \tilde{v})=(\zeta+h)(u, v)$ and $u, v$ are the Reynolds averaged components of velocities in the directions of $x$ any $y$ respectively; $f=2 \Omega \sin \sin \varphi$ is the Coriolis parameter, where $\Omega$ is the angular speed of the earth rotation and $\varphi$ is the latitude of the field of view; $g$ is the acceleration due to gravity. $\rho$ is the density of seawater that is considered to be uniform at the same density.

\subsubsection{Boundary conditions}

In this model, boundary condition consider a radiation type of boundary condition (Al Mohit, Yamashiro, Hashimoto, et al., 2018),

$u \cos \cos \alpha+v \sin \sin \alpha=-\left(\frac{g}{h}\right)^{\frac{1}{2}} \zeta$, for all $t \geq 0$

Where, $\alpha$ denotes the direction of the outward normal to the coast measured clockwise from the north direction. The radiation type boundary condition allows the propagation of energy only outwards from the interior in the form of simple progressive waves. The modified form of the equation (8) is used for the coastal boundaries. At the coastline, east boundary, southern boundary, and west boundary the direction angle $\alpha=0, \alpha=270, \alpha=180$, and $\alpha=90$ respectively. The following radiation types of boundary conditions are taken for open sea boundaries:

At the west boundary: $v+\left(\frac{g}{h}\right)^{\frac{1}{2}} \zeta=0$

At the east boundary: $v-\left(\frac{g}{h}\right)^{\frac{1}{2}} \zeta=0$

At the south boundary:

$u-\left(\frac{g}{h}\right)^{\frac{1}{2}} \zeta=-2\left(\frac{g}{h}\right)^{\frac{1}{2}} a \sin \sin \left(\frac{2 \pi t}{T}+\varphi\right)$

The normal components of the mean current are taken as zero at the closed boundaries of the mainland and the islands.

\subsubsection{Numerical procedure}

In order to estimate the appropriate water level due to a surge in the designated study area, it is important to investigate the activity of the cyclone over the area at least 3 days before crossing the coast. The study area is divided into three nested schemes. The prescribed nested schemes are: fine mesh scheme (FMS), coarse mesh scheme (CMS) and a very fine mesh scheme (VFMS). In this study, nesting is done in sequence from CMS to FMS and from FMS to VFMS. The CMS covers the domain $15^{\circ} \mathrm{N}$ to $23^{\circ} \mathrm{N}$ latitude and $85^{\circ} \mathrm{E}$ to 
$95^{\circ} \mathrm{E}$ longitude. In this mesh size, the grid space is $\Delta x=$ $15.08 \mathrm{~km}$ and $\Delta y=17.52 \mathrm{~km}$ related with the $60 \times 61$ grid points in the computation domain. In a similar fashion, FMS cover the area between the latitude $21^{\circ}-15^{\prime}$ to $23^{\circ} \mathrm{N}$ and $89^{\circ}$ $\mathrm{E}$ to $92^{\circ} \mathrm{E}$ longitudes with $92 \times 95$-grid point associated with the grid distance $\Delta x=2.15 \mathrm{~km}$ and $\Delta y=3.29 \mathrm{~km}$. To incorporate the landfall target area properly, the VFMS covers the area between $21.770 \mathrm{~N}$ to $23^{\circ} \mathrm{N}$ latitude and $90.40^{\circ} \mathrm{E}$ to $92^{\circ} \mathrm{E}$ longitudes. In this scheme, the grid size of the $\mathrm{x}$-axis (north-south direction) is $\Delta x=720.73 \mathrm{~m}$ and the $\mathrm{y}$-axis (east-west direction) $\Delta y=1142.39 \mathrm{~m}$ with $190 \times 145$ grid points. Every Number of grid points where the computation parameter $\zeta, u, v$ need to be computed. Before computing or running the model code, to ensure the stability of an explicit finite difference scheme. So that, the time step, $\Delta t$, should be related to the mesh size of $\Delta x, \Delta y$, and the ocean depth, $\mathrm{h}$, by the following relation of CFL (Courant-Friedrichs-Lewy) condition $\Delta t \leq \frac{\Delta x}{\sqrt{2 g h}}$.

After Setup all the conditions and consider the tidal condition at the open sea boundary to find the actual estimation. After that, run the model code and exchange the result in each scheme by using linear interpolation.

\section{RESULTS}

We have analyzed the cyclone track data to find the general scenario of cyclone behavior within the Bay of Bengal. Before the storm surge estimation, we have checked the data similarity with observed and simulated data. Therefore, we have compared the seasonal behavior of cyclones along this region of interest. The compared result is shown in Figure 3. More detail is discussed in the Discussion section.

In the discussion section, we have also discussed the central pressure of cyclones and landfall angle. The result of the behavior of central pressure and landfall angle due to climate change are shown in Figure 4 and Figure 5.

The 100 member's simulation of the present data shows the mean crossing angle is 91.0373 and the future ensemble of 90 member's simulation shows 93.9193 . This means that the future cyclone shifted 2.882 degrees northeast to the northwest side of Bangladesh coast, see Figure 5. After applying all the changes of landfall angle statistics in a known cyclone track then we found the different angled tracks. Figure 6 shows the changed cyclone tracks that are changed by the condition of the tracks analysis result.

To get the useful information about the surge height due the landfall angle of a cyclone. At first, we ran the model for the 1991 cyclone and got the model simulation result. We found that the simulated results make good agreement with observed data. After that, we have run the model for different tracks which are modified at different strike angles. We have discussed the climate change behavior on the Bay of Bengal cyclone and the landfall angle behavior due to climate change is discussed in the discussion section. To get the actual influence of strike angle on the water level elevation due to a storm, we run the model with changed information.

Figure 7 shows the surge height in different tide stations for the different cases. The result found that the surge height was reduced due to the landfall angle change. When the landfall occurred at an 85 degree angle, the surge height increased. But, the surge height decreased when the landfall angle was 93 degree. For each case, the surge height is changed according to the landfall angle. The maximum surge height fluctuation is about $80 \mathrm{~cm}$. Different tide stations show different water level elevation due to its topographical condition and cyclone position. In this simulation, we have chosen the 1991 cyclone that struck the Bangladesh coast on 30 April at 2 AM local time. The wind speed of this cyclone was $250 \mathrm{~km} \mathrm{~h}^{-1}$ and the central pressure was $918 \mathrm{hPa}$. The obtained result and the result from other studies are similar in different tide stations. The resulting fluctuation is about 1 meter. From the model simulation of the 1991 cyclone, the surge height was found near the Chittagong district at approximately 6 meters (20ft) approximately. The results of different scholars studies, our study and the observed data are shown in Table 1. Where the observed data is provided by the Bangladesh Government Authority BIWTA, Bangladesh Inland Water Transport Authority.

\section{DISCUSSION}

\subsection{Climate data analysis}

We have analyzed the d4PDF, MRI-AGCM and BMD data. The MRI-AGCM data and d4PDF data represent the model simulation climate data. The d4PDF data consist of historical climate simulation: 1951-2010, 100 members, non-warming simulation: 1951-2010, 100 members, +2K future climate simulation: 2031-2090, 54 members, +4K future climate simulation: 2051-2110, 90 members. In this study, we have analyzed historical climate simulation: 1951-2010, 100 members for present scenario and $+4 \mathrm{~K}$ future climate simulation: 2051-2110, 90 members for the future scenario. For both cases of the present climate scenario of d4PDF and MRI-AGCM we compare the seasonal behavior of cyclone occurrence with the occurrence number of BMD. The occurrence behavior makes good agreement with those data.
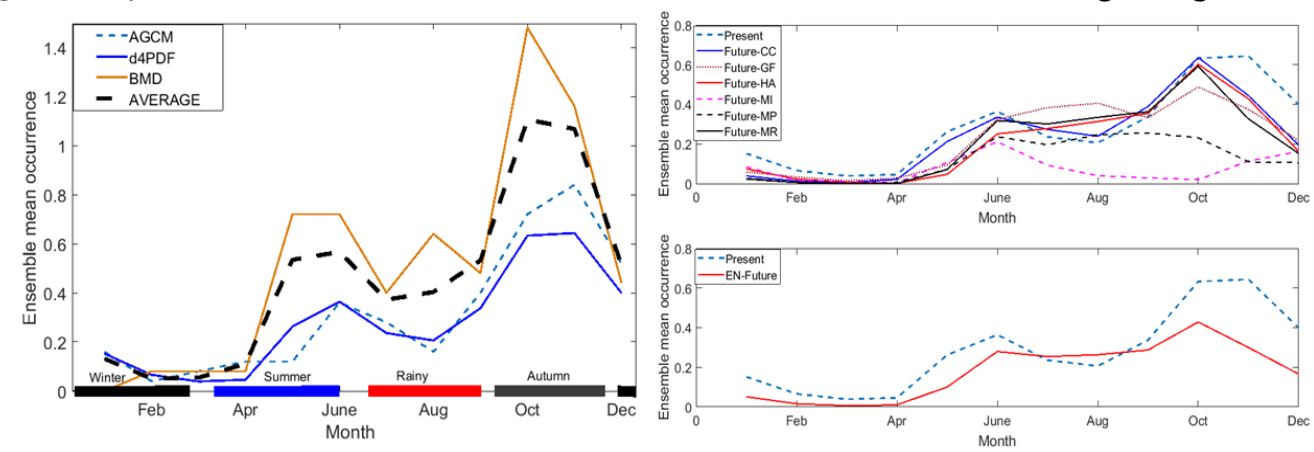

Figure 3. Tropical cyclone occurrence behavior. The left figure represents the comparison of cyclone occurrence in different models and observed data. The right side figure shows the comparison of present and future occurrence behavior. 


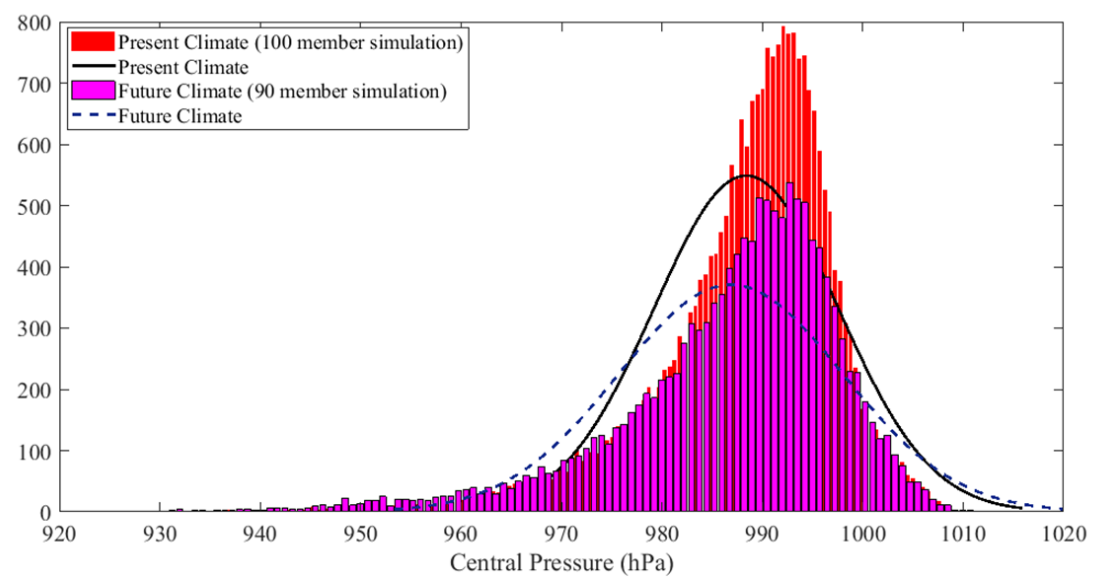

Figure 4. The histogram fitted the normal distribution of cyclone central pressure under present and future ensemble data.

Figure 3 represents the occurrence behavior of the different simulation results and observed data. From this figure, we have found that September to November is the cyclone-prone season of Bangladesh. This figure also found the similarity of seasonal variation with observed data and other model data. When we found the agreement result then we tried to analyze the central pressure behavior and landfall angle. The central pressure of the future ensemble simulation data represents the cyclone intensity information and the data shows the future intensity of a cyclone will be increased in this region. Figure 4 shows the bell curve of the central pressure distribution, which explains that the maximum intense cyclone occurrence will be increased in the future. For the present climate condition, the lower central pressure is less prevalent than the future cyclone central pressure. On the other hand, the normal distribution of the histogram fitted graph shows the mean of the central pressure lies between 985 to $995 \mathrm{hPa}$ for present climate conditions and 980 to $990 \mathrm{hPa}$ for future climate conditions. This shows that the intensity of the Bay of Bengal cyclone will be increased in future. After that, we used the novel technique to find the landfall angle of the cyclone. To find the landfall angle, we calculate the angle between the tangent of coastline and the point before landfall and after landfall. The crossing angle represents the angle between coastline and the cyclone path line. After analyzing the data, we have found the 100 member's simulation of the present data shows the mean crossing angle is 91.0373 and the future ensemble of 90 member's simulation shows 93.9193. This means that the future cyclone shifted 2.882 degrees northeast to the northwest side of Bangladesh coast, See Figure 5 . This deflected angle due to climate change is the notable information for the coastal researcher of Bangladesh. We have used this information to estimate the water level due to a storm. To estimate the water level elevation, we have used a developed storm surge model.

\subsection{Model result analysis}

Model input data was obtained from the Bangladesh Inland Water Transport Authority (BIWTA) and Bangladesh Meteorological Department (BMD). The model input data are cyclone 1991 track data, Bathymetry data and its relevant information. We have applied the landfall change angle to the known track of cyclone 1991 and changed the track one degree from 85 degrees to 93 degrees. Because, climate change has an impact on tropical cyclones (Miles, 2017; Walsh et al., 2019). Therefore, for this reason, the associated surge height changes in the coastal region of Bangladesh. Before running the model, we have prepared the virtual track which considers the different strike angles. The different strike angle was estimated from the AGCM and d4PDF data calibration (Hirahara et al., 2014; Mizuta et al., 2012; Murakami et al., 2012).
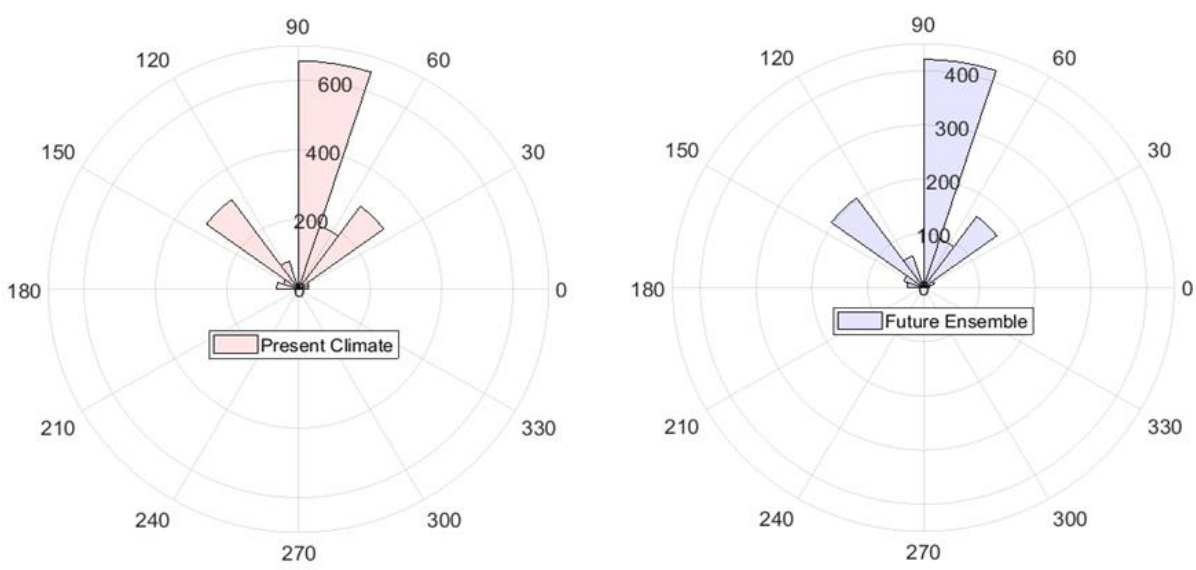

Figure 5. The left figure shows the polar histogram of the 100 members simulated on each track that strikes the Bangladesh coast. The right figure shows the polar histogram of future cyclone striking angle. 


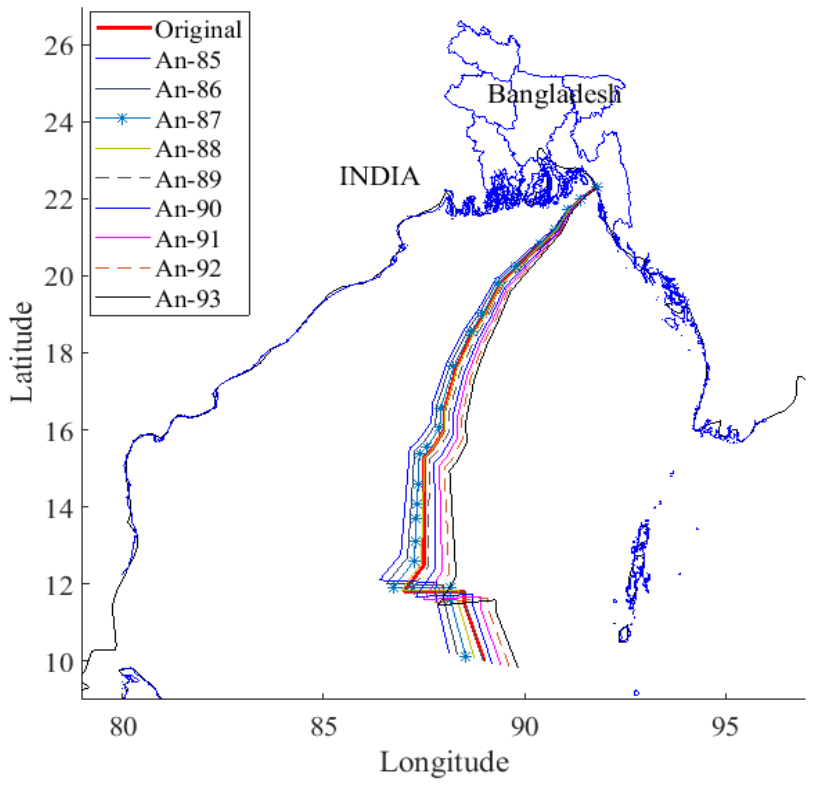

Figure 6. Different angle track with same landfall point.
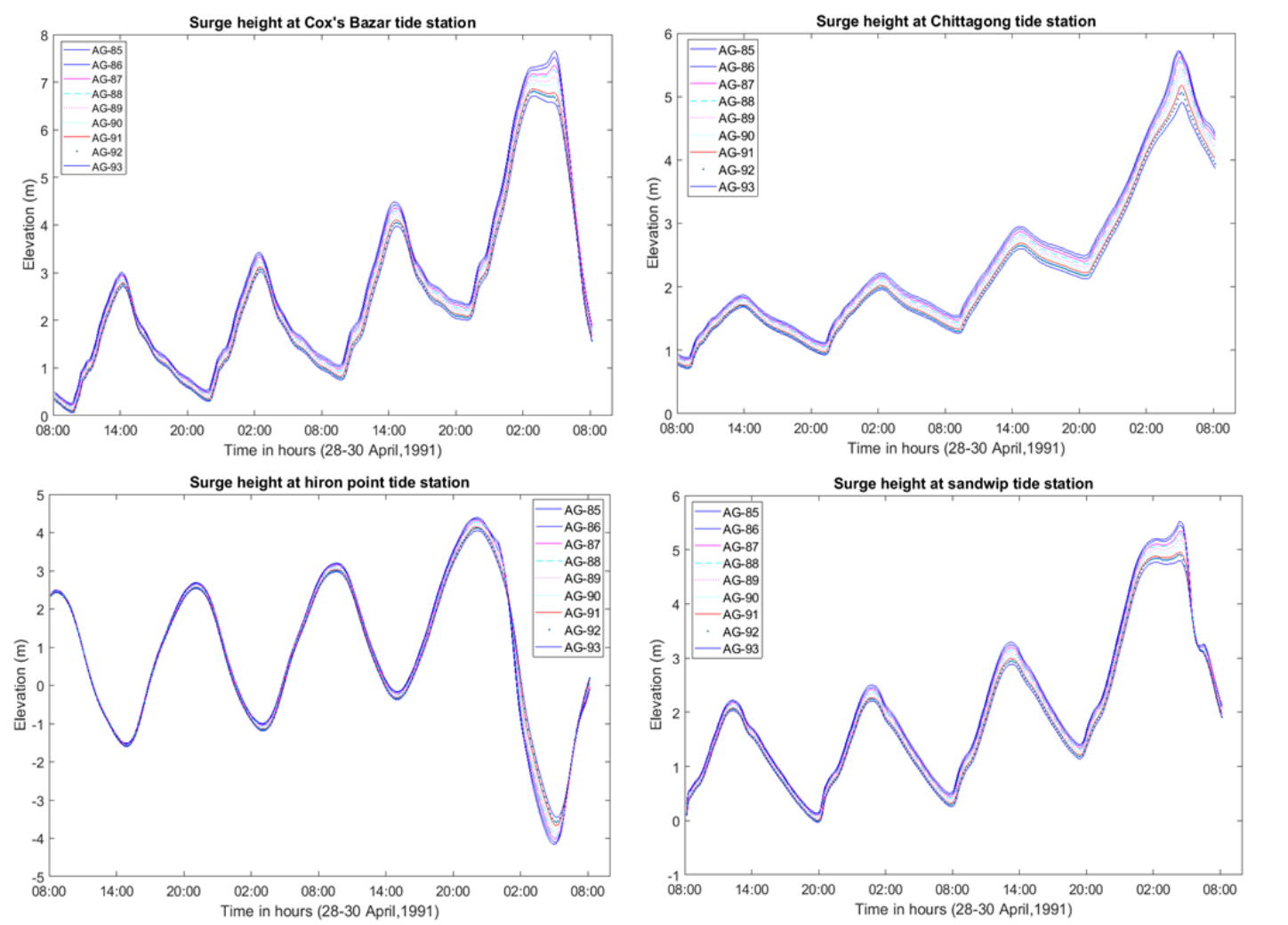

Figure 7. Surge height in different tidal stations for different landfall angles.

Firstly, we measured the actual strike angle of cyclone 1991 and we found that the angle is 88.97degree. After that we analyzed the cyclone track data that was simulated in present and future climate conditions (Baba, 2021; Du et al., 2011). From the cyclone strike angle analysis, we found that the strike angle is 91.0373 degrees for present climate conditions, 93.9193 degrees for future climate conditions. Considering this information, we have changed the original cyclone track in such a way that the virtual tracks are in between them. It should be noted that although the path of the storm has changed, other aspects of the storm (center pressure, wind speed, etc.) have not changed. We create different storm paths by changing the angle values and run the model for each different storm path. The storms were rotated at a certain angle, keeping the striking area fixed for each path of the storm. Indeed, the idea of this change in the path of the storm is adopted by looking at the characteristics of the storm that have changed under the influence of different climates (Chen et al., 2020). Figure 6 represents the one-degree change of landfall track on both sides from the original track. This figure shows the original track that strikes Bangladesh coast at 88.97 degree angle. Keeping the same point of landfall, the track feature is changed one degree considering the fluctuation of landfall angle. 
Table 1. Simulation result comparison

\begin{tabular}{|c|c|c|c|c|c|}
\hline Coastal Location & $\begin{array}{l}\text { Overall Max. } \\
\text { Water Level (m) } \\
\text { (Paul et al., } \\
\text { 2014) }\end{array}$ & $\begin{array}{c}\text { Simulated } \\
\text { Overall Max. } \\
\text { Water Level (m) } \\
\text { (Paul \& Ali, } \\
\text { 2019) }\end{array}$ & $\begin{array}{c}\text { Simulated Overall } \\
\text { Max. Water Level } \\
\text { (m) by FDM (Al } \\
\text { Mohit, Yamashiro, } \\
\text { Hashimoto, et al., } \\
\text { 2018) }\end{array}$ & $\begin{array}{l}\text { Simulated Max. } \\
\text { Water Level (m) }\end{array}$ & $\begin{array}{l}\text { Observed Overall } \\
\text { Max. Water Level } \\
\text { (m) }\end{array}$ \\
\hline Cox's Bazar & -- & 2.59 & 5.14 & 5.80 & 4.8 \\
\hline Chittagong & 6.25 & 6.30 & 6.10 & 5.87 & 5.4 \\
\hline Sitakunda & 5.78 & 6.02 & 4.48 & 4.90 & -- \\
\hline Sandwip & 5.63 & 5.89 & 5.30 & 4.80 & -- \\
\hline Companiganj & 7.28 & 6.78 & -- & 6.4 & 6.1 \\
\hline Hiron Point & 4.01 & 3.95 & 3.80 & 3.45 & 3.5 \\
\hline
\end{tabular}

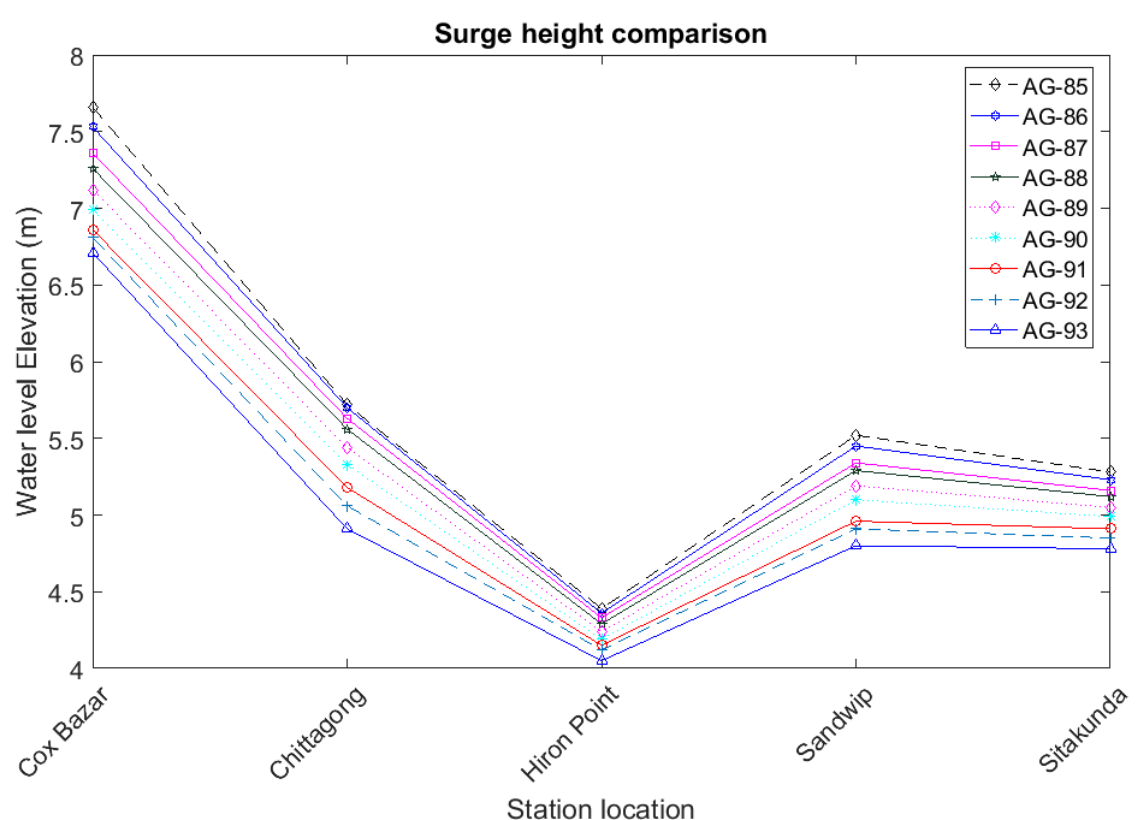

Figure 8. Overall surge height in different coastal locations.

However, the results are a little bit different from what we expected. From the data of storm paths obtained in different climatic conditions, we can see that most of the storm hitting at an angle of 89 degrees, i.e. the storm hitting in the northwest corner is a little higher. At first, we ran the model associated with the data from actual storms of 1991 and compared the results with other research findings and observed data. When the results of our simulations make good agreement with other studies then we use the model to estimate water levels for other storms (other storms vary depending on the landfall angle). From the obtained result, we can see that in the southwestern district of Cox's Bazar in Bangladesh, the 1991 storm had caused up to 6 meters of water level. However, we found that there is a slight decrease in the water level in this area for the landfall angle change. After that, the different tracks were used to simulate surge height considering the same parameter value as central pressure, maximum sustained wind velocity, the radius of the cyclone and so on except striking angle.

For the one parameter of track feature (landfall angle) analysis may not explain the future scenario of surge height changes. But, we can get some information from this study that the surge height will decrease if the cyclone strikes the Bangladesh coast at a greater than 90 degree angle.
Therefore, the cyclone track information shows that the future cyclone strikes Bangladesh coast through the mean landfall angle of 93.91 degrees. That's why the future surge height may decrease based on the one parameter analysis. In the near future, we will analyze the surge height considering the associated parameter impact. The overall storm surge features are shown in Figure 8. The small fluctuation is found in the Hiron point station. The reason behind this small fluctuation is the distance of the landfall position. However, it is evident that the surge height changes due to the same cyclone when the striking angle changes. However, the cyclone struck near the coast of Chittagong district, but we have investigated the surge height all over the Bangladesh coast. We have found in this study that the surge height reduces at Hiron point location when the cyclone struck the Chittagong coast. For the analysis of Different landfall angles of the track, we run the model for every track which separates according to the strike angle. We have found that the crossing angle fluctuation is approximately 2 to 3 degree north-east to the north-west direction in the coast of Bangladesh and for this reason maximum surge height was fluctuated by $80 \mathrm{~cm}$ approximately around the coast of Bangladesh. 


\section{CONCLUSION}

This study concentrated on the cyclone track behavior changes impact on storm surge height. The d4PDF data of cyclone track features shows that the landfall angle changed approximately 2.88 degrees northeast to northwest direction and due to this reason, the associated surge height may decrease depending upon the coastal location. This study found that the maximum surge height reduces $80 \mathrm{~cm}$ but the average surge height decreases about $20 \mathrm{~cm}$ in each degree when the landfall angle changes from 85 degrees to 93 degrees. So, it is found the cyclone strike from Southeast to Northwest direction is dangerous for the Chittagong coast.

\section{Acknowledgments}

The first author gives thanks to the authority of the University Grant Commission of Bangladesh for approving the relevant projects and funding for this study. In this study, we used a database to determine future climate change (d4PDF) policy, which was created under the SOUSEI program. The authors are also thankful to the Department of Mathematics, Islamic University, Kushtia, Bangladesh for their facilities.

\section{Declaration of competing interest}

The authors declare no competing financial or personal interests that may appear and influence the work reported in this paper.

\section{References}

Al Mohit, M. A., Yamashiro, M., Hashimoto, N., Mia, M. B., Ide, Y., \& Kodama, M. (2018). Impact Assessment of a Major River Basin in Bangladesh on Storm Surge Simulation. Journal of Marine Science and Engineering, 6(3), 99. https://doi.org/10.3390/jmse6030099

Al Mohit, M. A., Yamashiro, M., Ide, Y., Kodama, M., \& Hashimoto, N. (2018). Tropical Cyclone Activity Analysis Using MRI-AGCM and d4PDF Data. The 28th International Ocean and Polar Engineering Conference, Sapporo, Japan, June 2018.

Antony, C., \& Unnikrishnan, A. S. (2013). Observed characteristics of tide-surge interaction along the east coast of India and the head of Bay of Bengal. Estuarine, Coastal and Shelf Science, 131, 6-11. https://doi.org/10.1016/j.ecss.2013.08.004

Baba, Y. (2021). Influence of a spectral cumulus parametrization on simulating global tropical cyclone activity in an AGCM. Quarterly Journal of the Royal Meteorological Society, 147(735), 1170-1188. https://doi.org/10.1002/qj.3965

Chen, J., Wang, Z., Tam, C.-Y., Lau, N.-C., Lau, D.-S. D., \& Mok, H.-Y. (2020). Impacts of climate change on tropical cyclones and induced storm surges in the Pearl River Delta region using pseudo-global-warming method. Scientific Reports, 10(1), 1965. https://doi.org/10.1038/s41598-020-58824-8

Du, Y., Yang, L., \& Xie, S.-P. (2011). Tropical Indian Ocean Influence on Northwest Pacific Tropical Cyclones in Summer following Strong El Niño. Journal of Climate, 24(1),

315-322.
Dube, S. K. (2012). Prediction of Storm Surges in the Bay of Bengal. Tropical Cyclone Research and Review, 1(1), 67-74. https://doi.org/10.6057/2012TCRR01.08

Hirahara, S., Ishii, M., \& Fukuda, Y. (2014). Centennial-Scale Sea Surface Temperature Analysis and Its Uncertainty. Journal of Climate, 27(1), 57-75. https://doi.org/10.1175/JCLI-D-12-00837.1

Hussain, M. A., \& Tajima, Y. (2017). Numerical investigation of surge-tide interactions in the Bay of Bengal along the Bangladesh coast. Natural Hazards, 86(2), 669-694. https://doi.org/10.1007/s11069-016-2711-4

Hussain, M. A., Tajima, Y., Hossain, M. A., \& Das, P. (2017). Impact of Cyclone Track Features and Tidal Phase Shift upon Surge Characteristics in the Bay of Bengal along the Bangladesh Coast. Journal of Marine Science and Engineering, 5(4), 52. https://doi.org/10.3390/jmse5040052

Jaman, T., Dharanirajan, K., \& Shivaprasad Sharma, S. V. (2021). Assessment of impact of cyclone hazard on social vulnerability of Bhadrak District of Odisha State during Phailin Cyclone in 2013 and Titli Cyclone in 2018 using multi-criteria analysis and geospatial techniques. International Journal of Disaster Risk Reduction, 53, 101997. https://doi.org/10.1016/j.ijdrr.2020.101997

Kotal, S. D., \& Bhattacharya, S. K. (2013). Tropical cyclone Genesis Potential Parameter (GPP) and it's application over the north Indian Sea. MAUSAM, 64(1), 149-170. https://doi.org/10.54302/mausam.v64i1.663

Mamnun, N., Bricheno, L. M., \& Rashed-Un-Nabi, M. (2020). Forcing ocean model with atmospheric model outputs to simulate storm surge in the Bangladesh coast. Tropical Cyclone Research and Review, 9(2), 117-134. https://doi.org/10.1016/j.tcrr.2020.04.002

Miles, T. (2017). Storm Harvey's rainfall likely linked to climate change: U.N. Reuters. https://www.reuters.com/article/us-storm-harveyun-idUKKCN1B9190

Mizuta, R., Yoshimura, H., Murakami, H., Matsueda, M., Endo, H., Ose, T., Kamiguchi, K., Hosaka, M., Sugi, M., Yukimoto, S., Kusunoki, S., \& Kitoh, A. (2012). Climate Simulations Using MRI-AGCM3.2 with 20-km Grid. Journal of the Meteorological Society of Japan. Ser. II, 90A, 233-258. https://doi.org/10.2151/jmsj.2012-A12

Murakami, H., Mizuta, R., \& Shindo, E. (2012). Future changes in tropical cyclone activity projected by multi-physics and multi-SST ensemble experiments using the $60-\mathrm{km}$ mesh MRI-AGCM. Climate Dynamics, 39(9), 25692584. https://doi.org/10.1007/s00382-011-1223-x

Musinguzi, A., \& Akbar, M. K. (2021). Effect of Varying Wind Intensity, Forward Speed, and Surface Pressure on Storm Surges of Hurricane Rita. Journal of Marine Science and Engineering, 9(2), 128. https://doi.org/10.3390/jmse9020128

Paul, G. C., \& Ali, M. E. (2019). Numerical storm surge model with higher order finite difference method of lines for the coast of Bangladesh. Acta Oceanologica Sinica, 38(6), 100-116. https://doi.org/10.1007/s13131-0191385-7 
Paul, G. C., \& Ismail, A. I. M. (2012). Numerical modeling of storm surges with air bubble effects along the coast of Bangladesh. Ocean Engineering, 42, 188-194. https://doi.org/10.1016/j.oceaneng.2012.01.006

Paul, G. C., \& Ismail, A. I. M. (2013). Contribution of offshore islands in the prediction of water levels due to tidesurge interaction for the coastal region of Bangladesh. Natural Hazards, 65(1), 13-25. https://doi.org/10.1007/s11069-012-0341-z

Paul, G. C., Ismail, A. I. M., \& Karim, M. F. (2014). Implementation of method of lines to predict water levels due to a storm along the coastal region of Bangladesh. Journal of Oceanography, 70(3), 199-210. https://doi.org/10.1007/s10872-014-0224-x

Paul, G. C., Khatun, R., Ali, E., \& Rahman, M. M. (2021). Importance of an efficient tide-surge interaction model for the coast of Bangladesh: a case study with the tropical cyclone Roanu. Journal of Coastal Conservation, 25(1), 12.
Ramos-Valle, A. N., Curchitser, E. N., \& Bruyère, C. L. (2020). Impact of Tropical Cyclone Landfall Angle on Storm Surge Along the Mid-Atlantic Bight. Journal of Geophysical Research: Atmospheres, 125(4), e2019JD031796. https://doi.org/10.1029/2019JD031796

Shankar, C. G., \& Behera, M. R. (2019). Wave Boundary Layer Model based wind drag estimation for tropical storm surge modelling in the Bay of Bengal. Ocean Engineering, 191, 106509. https://doi.org/10.1016/j.oceaneng.2019.106509

Tadesse, M., Wahl, T., \& Cid, A. (2020). Data-Driven Modeling of Global Storm Surges. Frontiers in Marine Science, 7. https://doi.org/10.3389/fmars.2020.00260

Walsh, K. J. E., Camargo, S. J., Knutson, T. R., Kossin, J., Lee, T. C., Murakami, H., \& Patricola, C. (2019). Tropical cyclones and climate change. Tropical Cyclone Research and Review, 8(4), 240-250. https://doi.org/10.1016/j.tcrr.2020.01.004 